\title{
Macroscopically uniform electrodeposited ZnO films on conducting glass by surface tension modification and consequent demonstration of significantly improved $\mathrm{p}-\mathrm{n}$ heterojunctions
}

\author{
Kevin P. Musselman ${ }^{\mathrm{a}, *}$, Talia Gershon ${ }^{\mathrm{a}}$, Lukas Schmidt-Mende $^{\mathrm{b}}$, Judith L. MacManus-Driscoll ${ }^{\mathrm{a}}$ \\ a Department of Materials Science, University of Cambridge, Pembroke St., Cambridge, CB2 3QZ, United Kingdom \\ ${ }^{\mathrm{b}}$ Department of Physics and Center for Nanoscience (CeNS), Ludwig-Maximilians University Amalienstr. 54, D-80799 Munich, Germany
}

\begin{abstract}
A B S T R A C T
An alternative water-ethanol zinc nitrate solution is demonstrated to completely eliminate macroscopic defects that are normally prevalent in $\mathrm{ZnO}$ films electrochemically deposited from aqueous zinc nitrate solutions. The inclusion of $25 \%$ ethanol (by volume) reduces the surface tension of the mixture and eliminates bubble formation on the conducting glass surface during deposition. To demonstrate the importance of film uniformity, the $\mathrm{ZnO}$ films are employed in $\mathrm{ZnO}_{-} \mathrm{Cu}_{2} \mathrm{O} \mathrm{n}-\mathrm{p}$ heterojunctions and an order of magnitude improvement in diode behaviour is observed.
\end{abstract}

\section{Introduction}

In recent years, zinc oxide has emerged as one of the most important functional oxide materials. It has a wide range of properties, owing to its rich defect chemistry and receptiveness to doping. Intrinsically, $\mathrm{ZnO}$ is a wide-bandgap, n-type semiconductor, with a bandgap of approximately $3.3 \mathrm{eV}$. It has applications in optoelectronics, energy harvesting, and as a sensor or catalyst material [1-3]. Fabrication of continuous ZnO layers free of macroscopic defects over device-suitable areas on transparent conducting substrates is essential for these applications and solution-based synthesis is desirable. Electrochemical deposition (electrodeposition) of $\mathrm{ZnO}$ from solutions near room temperature is a powerful, inexpensive fabrication route, which permits the synthesis of thin films on a variety of conducting substrates with different form factors. Electrodeposition of $\mathrm{ZnO}$ has traditionally been performed using aqueous zinc nitrate $\left(\mathrm{Zn}\left(\mathrm{NO}_{3}\right)_{2}\right)$ [4] or zinc chloride $\left(\mathrm{ZnCl}_{2}\right)$ solutions [5]. The nucleation of $\mathrm{ZnO}$ on transparent conducting oxide substrates is relatively poor and stability considerations preclude the use of large concentrations of zinc chloride [6], such that self-assembling, porous nanorod or nanowire structures are typically obtained by electrodeposition from zinc chloride mixtures [5-7]. ZnO growth in nitrate solutions is typically faster and less

\footnotetext{
* Corresponding author. Tel.: +44 1223767 919; fax: +44 1223334567

E-mail address: kpdm2@cam.ac.uk (K.P. Musselman).
}

anisotropic, such that larger grains and planar films can be more easily synthesized. Compact functional ZnO layers are necessary for many of the aforementioned applications (e.g. photovoltaics, lightemitting diodes), such that electrodeposition from zinc nitrate solutions was investigated in this work. $\mathrm{ZnO}$ formation in nitrate solutions proceeds according to the reactions:

$$
\begin{aligned}
& \mathrm{NO}_{3(\mathrm{aq})}{ }^{-}+\mathrm{H}_{2} \mathrm{O}_{(\mathrm{l})}+2 \mathrm{e}^{-} \rightarrow \mathrm{NO}_{2(\mathrm{aq})}{ }^{-}+2 \mathrm{OH}_{(\mathrm{aq})}{ }^{-} \\
& \mathrm{Zn}_{(\mathrm{aq})}{ }^{2+}+2 \mathrm{OH}_{(\mathrm{aq})}{ }^{-} \rightarrow \mathrm{ZnO}_{(\mathrm{s})}+\mathrm{H}_{2} \mathrm{O}_{(\mathrm{l})}
\end{aligned}
$$

Many studies have examined the influence of the electrodeposition parameters, precursor concentration, and substrate type on the microscopic properties of $\mathrm{ZnO}$ thin films electrodeposited from zinc nitrate solutions [4,8-14]. The macroscopic homogeneity of the thin films, however, has received little attention. In this work, polycrystalline $\mathrm{ZnO}$ films are produced by electrodeposition on indium-tin-oxide (ITO)/glass substrates suitable for optoelectronic applications. Despite the formation of continuous polycrystalline grains on the microscopic scale, macroscopic discontinuities in the synthesized films are found to result from the formation of gas bubbles on the ITO surface during electrodeposition. At typical deposition potentials in zinc nitrate solutions, it is expected that water is decomposed and hydrogen evolved at the cathode according to:

$$
2 \mathrm{H}_{2} \mathrm{O}_{(\mathrm{l})}+2 \mathrm{e}^{-} \rightarrow \mathrm{H}_{2(\mathrm{~g})}+2 \mathrm{OH}_{(\mathrm{aq})}{ }^{-}
$$

It is known that for aqueous solutions, bubbles can be produced at regions supersaturated with dissolved hydrogen, inhibiting the 
deposition of the desired material and yielding pinholes [15,16]. In some studies, hydrogen bubbles have been utilized to produce useful nanostructures such as nanoporous $\mathrm{ZnO}$ [17] and $\mathrm{Zn}$ nanotubes [18]. However for many applications where multi-layer structures are required, pinhole free $\mathrm{ZnO}$ films are essential to prevent contact between adjacent layers.

Peulon and Lincot previously reported that a polarization pretreatment in oxygenated solutions without zinc could be used to improve the nucleation of $\mathrm{ZnO}$ on transparent conducting substrates to produce dense films [6]. In particular, it was suggested that polarization in a basic solution increases the density of hydroxyl groups on the substrate, which enhances nucleation [19]. It is expected that accelerated nucleation limits the exposure of the conducting substrate to the aqueous solution, preventing the accumulation of $\mathrm{H}_{2}$ gas and the formation of bubbles. Such polarization treatments were employed in this work, but were found to be unreliable at preventing the formation of bubbles and associated film defects. Others have developed a two-step electrodeposition method to improve $\mathrm{ZnO}$ nucleation and resulting film uniformity $[10,14]$. This technique, however, necessitates the introduction of an electrodeposited seed layer of inferior crystalline quality, consisting of randomly oriented nanoparticles.

In light of these findings, an alternative method is presented here to electrodeposit compact $\mathrm{ZnO}$ films free of macroscopic defects using a simple one-step deposition technique. In this work, zinc nitrate solutions are mixed with varying concentrations of ethanol, which is miscible with water, to prevent the formation of bubbles on the conductive substrate. Organic solvents are generally considered to be superior suspension medium for electrochemical reactions, as they avoid issues associated with the hydrolysis of water [15]. Additionally, the surface tension of water is known to decrease with the addition of alcohols. Water-alcohol mixtures have previously been employed to produce electrochemically synthesized $\mathrm{ZnO}$ structures such as nanobetls, nanorods, and platelets $[20,21]$, and to improve the wettability of hydrophobic polystyrene templates in zinc nitrate solutions [22]. To our knowledge however, it has not been demonstrated that alcoholcontaining solutions can be used to improve the macroscopic continuity of electrodeposited $\mathrm{ZnO}$ thin films. In this work, the introduction of a suitable quantity of ethanol is found to result in the deposition of $\mathrm{ZnO}$ thin films of excellent homogeneity on both the micro and macro scales, with no macroscopic defects visible over substrate areas of approximately $2 \mathrm{~cm}^{2}$.

The importance of macroscopic film quality is demonstrated by comparing the performance of $\mathrm{ZnO}$ films synthesized from pure aqueous and surface tension modified (STM) zinc nitrate solutions in electrochemically synthesized $\mathrm{ZnO}-\mathrm{Cu}_{2} \mathrm{O} \mathrm{n}-\mathrm{p}$ heterojunctions. Improved diode properties are observed for heterojunctions utilizing $\mathrm{ZnO}$ films free of macroscopic defects. Such heterojunctions are vital in many applications such as photovoltaics, photodetectors, light-emitting diodes, and lasers [23-27].

\section{Experimental}

Commercial substrates (Praezisions Glas \& Optik, $14 \mathrm{~mm} \times 14 \mathrm{~mm} \times 0.7 \mathrm{~mm}$ ) were used and consisted of an approximately $180 \mathrm{~nm}$ thick ITO layer (sheet resistance less than $10 \Omega \mathrm{sq}^{-1}$ ) on soda glass. All substrates were thoroughly cleaned in an ultrasonic bath with acetone and iso-propanol for 20 min prior to use.

A polarization pre-treatment (identical to that used by Izaki et al. [28]) was performed on some of the substrates to examine the enhancement in $\mathrm{ZnO}$ nucleation. A $10 \mathrm{~mA} \mathrm{~cm}^{-2}$ current was applied to the substrates for durations of $5-60 \mathrm{~s}$ in $1 \mathrm{M} \mathrm{NaOH}$.

Electrodeposition of both the $\mathrm{ZnO}$ and $\mathrm{Cu}_{2} \mathrm{O}$ was performed using a standard three-electrode cell in aqueous electrolytes of dissolved precursors. All chemicals used were reagent grade, and the water purified (resistivity greater than $16 \mathrm{M} \Omega \mathrm{cm}$ ). A Princeton Applied Research Model 363 Potentiostat/Galvanostat was used to supply a constant deposition potential or current. The substrates were electrically connected with an insulated wire and $\mathrm{Ag}$ paste, which were masked using Kapton polyimide tape. $\mathrm{A} \mathrm{Ag} / \mathrm{AgCl}$ reference electrode in a saturated aqueous $\mathrm{KCl}$ solution was employed $\left(+0.20 \mathrm{~V}\right.$ vs. SHE), with a $6.25 \mathrm{~cm}^{2}$ inert platinum counter electrode. The sample and platinum electrodes were placed approximately $1 \mathrm{~cm}$ apart in the deposition solution and the reference electrode was placed immediately adjacent to the sample surface. The depositions were performed under computer control and the amount of charge collected at the working electrode was used to estimate the nominal thickness of material deposited.

$\mathrm{ZnO}$ films with a nominal thickness of $550 \mathrm{~nm}$ were deposited from $0.08 \mathrm{M}$ zinc nitrate solutions with varying water:ethanol ratios at $74{ }^{\circ} \mathrm{C}$ and $-0.85 \mathrm{~V}$ vs. $\mathrm{Ag} / \mathrm{AgCl}$. It is important to note that ethanol is a flammable liquid with an auto-ignition temperature around $365^{\circ} \mathrm{C}$ and a flash point of approximately $13^{\circ} \mathrm{C}$, which means it readily vaporises to form an ignitable mixture. Diluting it with water increases the flash point to higher temperatures; for a $25 \%$ ethanol concentration (by volume), a flash point of approximately $24^{\circ} \mathrm{C}$ is expected [29]. Thus while the mixture used here is stable at room temperature, heating it above $24^{\circ} \mathrm{C}$ evaporates enough fluid to form a combustible concentration. To minimize risks associated with this solution, a small amount $(30 \mathrm{~mL})$ was used for each deposition and heated in a water bath away from any likely ignition sources. The depositions were performed in a properly ventilated area to prevent the build-up of gaseous ethanol.

$\mathrm{Cu}_{2} \mathrm{O}$ was deposited galvanostatically at $-1.0 \mathrm{~mA} \mathrm{~cm}^{-2}$ onto the

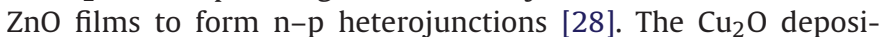
tion solution consisted of $0.4 \mathrm{M} \mathrm{CuSO}_{4} / 3 \mathrm{M}$ lactic acid at $40^{\circ} \mathrm{C}$, to which $4 \mathrm{M} \mathrm{NaOH}$ was added to adjust the $\mathrm{pH}$ to approximately 12.5. Typical $\mathrm{ZnO}$ depositions took approximately $10 \mathrm{~min}$ for a nominal thickness of $550 \mathrm{~nm}$, and $33 \mathrm{~min}$ was required to deposit a $\mathrm{Cu}_{2} \mathrm{O}$ film approximately $3 \mu \mathrm{m}$ thick. Annealing of the heterojunctions was performed at $100^{\circ} \mathrm{C}$ on a hotplate. For the fabrication of photovoltaic $\mathrm{ZnO}-\mathrm{Cu}_{2} \mathrm{O}$ diodes, the $\mathrm{Cu}_{2} \mathrm{O}$ deposition solution was buffered with a suitable quantity of sacrificial $\mathrm{ZnO}$ species to prevent unwanted etching of the functional $\mathrm{ZnO}$ film, as reported recently [24].

Scanning electron micrographs were obtained using a LEO VP1530 field emission scanning electron microscope (SEM). Film crystallinity was examined using a Bruker D8 theta/theta X-ray diffraction (XRD) system with $\mathrm{Cu}$ Kalpha radiation $(\lambda=0.15418 \mathrm{~nm}$ ) and a LynxEye position sensitive detector. Photoluminescence studies were performed at room temperature using an ACCENT RPM 2000 compound semiconductor photoluminescence system equipped with a Nd:YAG laser of wavelength $266 \mathrm{~nm}$.

Gold or silver contacts (approximately $0.15 \mathrm{~cm}^{2}$ active area) were evaporated onto the $\mathrm{Cu}_{2} \mathrm{O}$ using a $\mathrm{BOC}$ Edwards resistance evaporator to form an ohmic contact and current density-potential (j-E) measurements were performed using a Keithley 2400 SourceMeter with a custom-made LabView program. A solar simulator equipped with AM $1.5 \mathrm{G}$ filters was used at $100 \mathrm{~mW} \mathrm{~cm}^{-2}$ intensity. Intensity calibration was performed using an ISE Fraunhofer Institute certified silicon reference diode equipped with a KG5 filter to minimize spectral mismatch errors.

\section{Results and discussion}

\subsection{Synthesis and characterization of $\mathrm{ZnO}$ films from} water-ethanol solutions

Fig. 1 (a) and (b) displays SEM images of a $\mathrm{ZnO}$ film $(550 \mathrm{~nm}$ nominal thickness) deposited from a pure aqueous zinc nitrate 


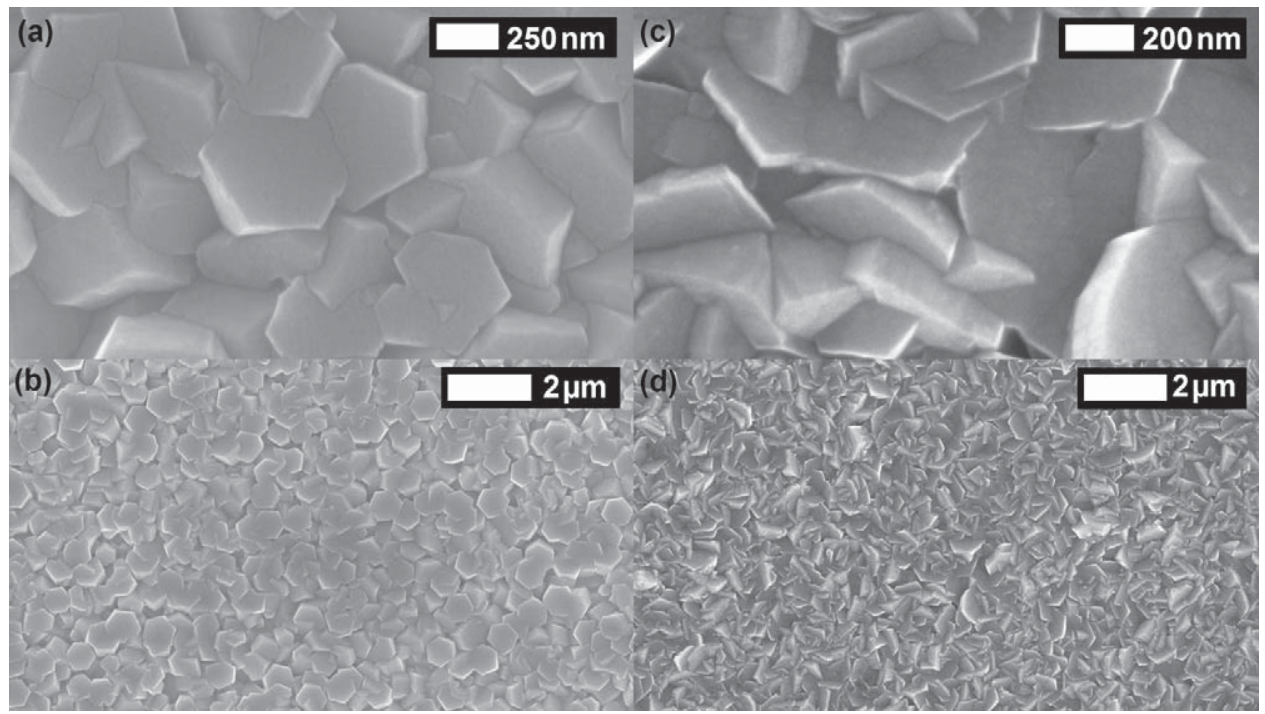

Fig. 1. SEM images of $\mathrm{ZnO}$ films with a nominal thickness of $550 \mathrm{~nm}$ electrodeposited at $74{ }^{\circ} \mathrm{C}$ and $-0.85 \mathrm{~V}$ vs. $\mathrm{Ag} / \mathrm{AgCl}$ from (a and b) pure aqueous and (c and d) $25 \% / 75 \%$ ethanol-water zinc nitrate solutions. The resulting films are polycrystalline, which at high magnifications show densely packed hexagonal grains. At lower magnifications, macroscopic pores are visible in the film synthesized using the aqueous solution (see Fig. 2 (c) and (d)).

solution. The film was found to be continuous on the microscopic scale, and was composed of densely packed hexagonal $\mathrm{ZnO}$ grains with dimensions of approximately $500 \mathrm{~nm}$. Macroscopically, however, pinholes were visible by eye in the film. An optical image (Fig. 2 (a)) shows the presence of bubbles on the ITO surface, which formed during $\mathrm{ZnO}$ deposition. A SEM image of an individual bubble hole in the $\mathrm{ZnO}$ film is shown in Fig. 2 (c). Fig. 2 (d) shows a SEM image of a ZnO film that has nucleated on the bubble surface, adopting the shape of the bubble contour.

Stirring of the solution during deposition was found to be insufficient to prevent bubble formation. Likewise, horizontal orientation of the substrates did not reduce bubble formation or adherence. While periodic agitation of samples did remove bubbles from the surface, subsequent coverage of the exposed ITO was found to be poor, as shown in Fig. 3, due to preferential growth on the surrounding $\mathrm{ZnO}$. Polarization pre-treatment of the substrates immediately before their insertion in the aqueous zinc nitrate electrodeposition solution was found to enhance nucleation and limit the formation of bubbles on the ITO surface. However, the polarization method was not found to be suitably reliable; a smaller concentration of bubble holes was still found on many ZnO films.

Bubble formation on ITO surfaces during $\mathrm{ZnO}$ depositions from solutions with increasing ethanol concentrations was then studied. A dramatic reduction in bubble formation was observed with the addition of ethanol. Smaller concentrations of bubbles and holes were still visible for ethanol volume concentrations up to $16 \%$, and only a few holes could be observed visually when the concentration was increased to $22 \%$. When a $25 \% / 75 \%$ ethanol-water mixture

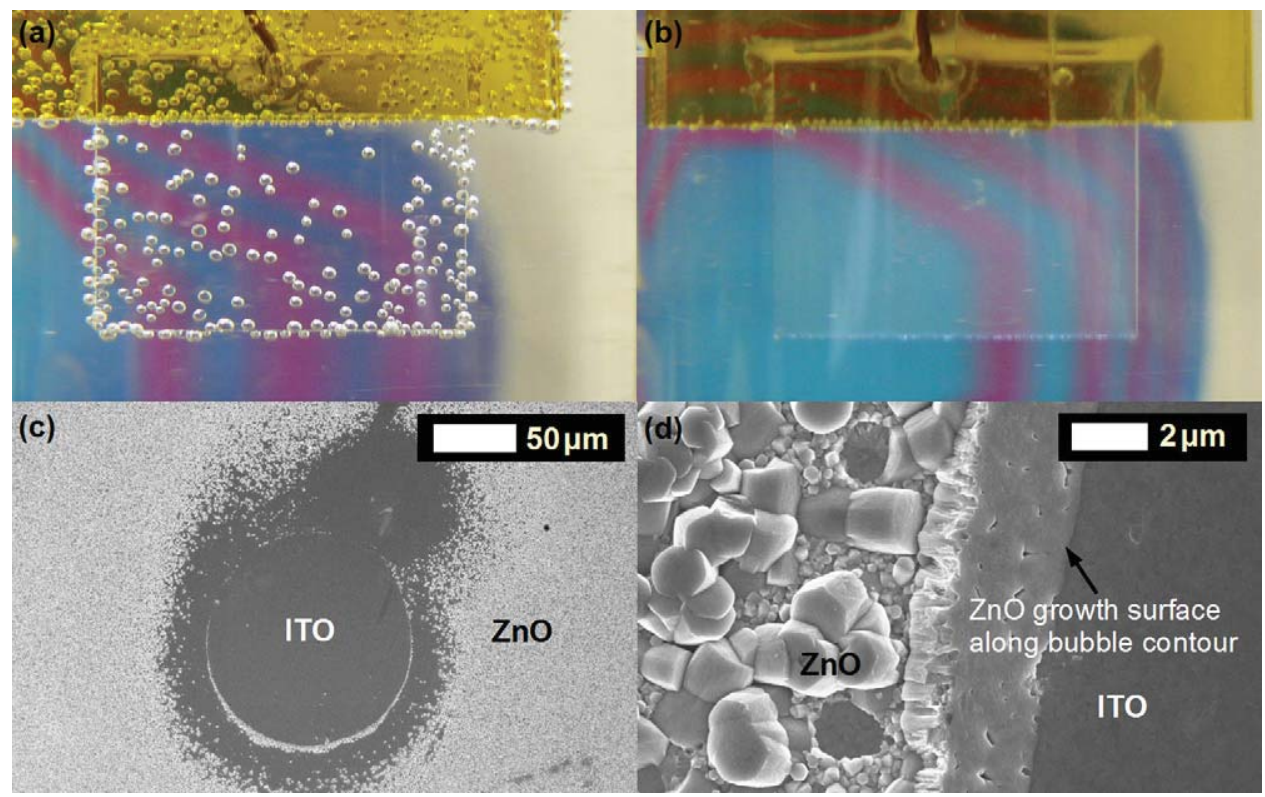

Fig. 2. The formation of gaseous hydrogen bubbles on the ITO surface during electrodeposition produces macroscopic discontinuities in ZnO films when synthesized from pure aqueous zinc nitrate solutions. (a) Optical image of surface of ITO during electrodeposition. Note that the image is distorted by viewing through a circular glass beaker (ITO substrate is $1.4 \mathrm{~cm} \times 1.4 \mathrm{~cm})$. (b) Use of a STM $(25 \% / 75 \%$ ethanol-water) zinc nitrate solution was found to completely eliminate the formation of bubbles on the ITO surface during deposition, due to a lower surface tension for the solution. (c) SEM image of a macroscopic defect in a $\mathrm{ZnO}$ film (550 nm nominal thickness) synthesized from an aqueous solution. (d) $\mathrm{ZnO}$ growth was observed to follow the contour of the bubbles, leaving ITO exposed. 


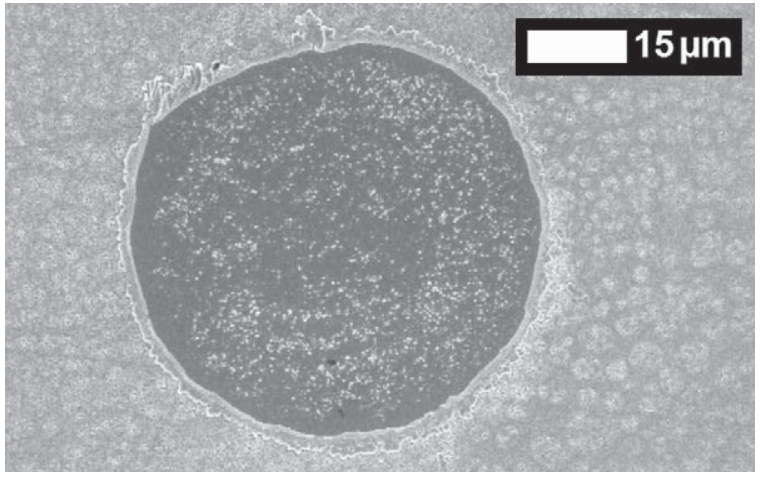

Fig. 3. Agitation of the ITO to remove the bubbles subsequently resulted in only partial filling of the defects.

was used, no bubbles were visible by eye on the ITO surface during deposition, as shown in Fig. 2 (b), and no bubble holes whatsoever could be viewed in the microscope. Fig. 1 (c) and (d) displays SEM images of continuous $\mathrm{ZnO}$ films deposited from $25 \%$ ethanol solutions. SEM imaging of film cross-sections revealed thickness similar to the nominal values, indicating a Faradaic efficiency close to $100 \%$ for electrodeposition from both pure aqueous and surface tension modified (STM) solutions.

The dramatic reduction in macroscopic film defects is directly attributable to the addition of ethanol. Less hydrogen evolution is expected at the lower water concentration, and the addition of alcohol is known to reduce the dielectric constant of the solvent, and hence the thickness of the double-layer, enhancing particle coagulation and film nucleation [15]. Most importantly, this 25\% by volume ethanol addition corresponds to an ethanol mass fraction of approximately $20 \%$, for which the surface tension has previously been measured to be approximately half of that of pure water [30]. Gaseous species can more easily escape from the surface of the ITO substrate, preventing the formation of bubbles and their associated defects. Unless otherwise specified, it can be assumed that an ethanol volume concentration of $25 \%$ was employed for the synthesis of STM ZnO films throughout the remainder of this work.

XRD data for $\mathrm{ZnO}$ films synthesized using both pure aqueous (a) and STM (b) zinc nitrate solutions is shown in Fig. 4. All peaks other than those resulting from the ITO substrate correspond to reflections from the wurtzite $\mathrm{ZnO}$ structure. In agreement with a recent study that reported the influence of alcohol additives on the orientation of electrodeposited $\mathrm{ZnO}$ films [31], it is seen in Fig. 4

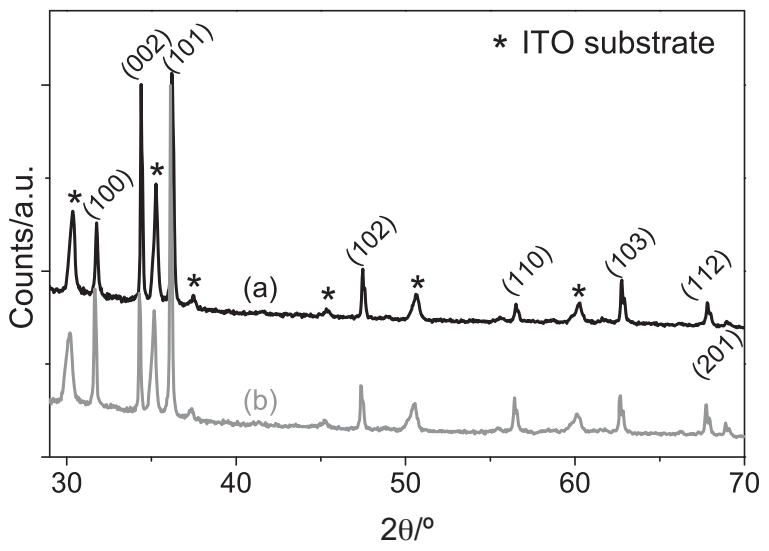

Fig. 4. XRD data for $\mathrm{ZnO}$ films electrodeposited from (a) pure aqueous and (b) STM zinc nitrate solutions. All reflections are attributable to wurtzite ZnO. Deposition from an ethanol-containing solution produced polycrystalline films composed of grains of various orientations.

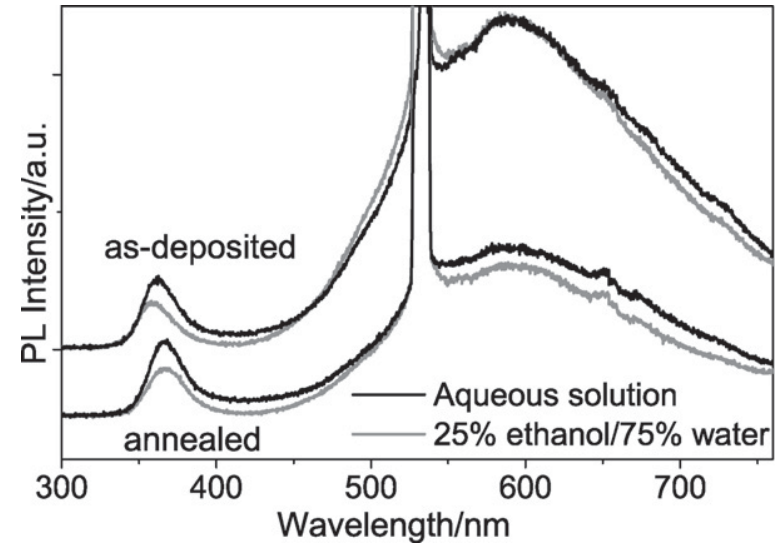

Fig. 5. Photoluminescence data for $\mathrm{ZnO}$ films electrodeposited from pure aqueous and STM zinc nitrate solutions, both before and after annealing at $100^{\circ} \mathrm{C}$ for $1 \mathrm{~h}$.

that the films synthesized from $25 \% / 75 \%$ ethanol-water solutions had roughly equal contributions from different crystallographic orientations, whereas the $\mathrm{ZnO}$ films deposited from pure aqueous solutions were characterized by a stronger $c$-axis orientation. In the study, the reduction in c-axis orientation was attributed to the decrease in the dielectric constant of the deposition solution with increasing alcohol content, which enables the accumulation of $\mathrm{ZnO}$ crystal faces of lower polarity. It was argued that the polar $(001)$ $\mathrm{ZnO}$ plane is stabilized in a pure aqueous solution where the dielectric constant is higher. The variation in crystallographic orientation of the hexagonal $\mathrm{ZnO}$ grains is evident in Fig. 1 for films synthesized from pure aqueous ( $a$ and b) and STM (c and d) solutions. The resulting grain size for the two deposition methods, however, is seen to be identical and similarly sharp diffraction peaks were observed for both solutions. Thus while the orientation of the $\mathrm{ZnO}$ film is influenced, the rates of nucleation and growth do not appear to be significantly influenced by the presence of ethanol.

Photoluminescence data for $\mathrm{ZnO}$ films synthesized using both pure aqueous and STM zinc nitrate solutions is shown in Fig. 5 for as-deposited films, as well as after annealing for $1 \mathrm{~h}$ at $100^{\circ} \mathrm{C}$. An ultra-violet (UV) peak is observed for both films, which corresponds to near band-edge emission. A broad trap-state photoluminescence peak is also observed for both $\mathrm{ZnO}$ depositions, which has previously been attributed to point defects such as interstitials, vacancies, and impurities, as well as surface defects [32-35]. The sharp peak at $532 \mathrm{~nm}$ within the defect band corresponds to a harmonic of the excitation laser. The width of the trap-state peak suggests the presence of a variety of defects in the electrodeposited films, although it is noted that the peak is centred at approximately $590 \mathrm{~nm}$; photoluminescence at this wavelength has been reported to correspond to the presence of hydroxyl groups [36]. A slightly smaller UV peak intensity relative to the trap-state peak intensity is observed in Fig. 5 for deposition from the ethanol-containing solution. A decrease in the ratio of the UV to trap-state peak intensity is often ascribed to a reduction in $\mathrm{ZnO}$ crystalline quality [37], however, several studies have noted that this correlation is not always accurate, as the peak intensity ratio may vary more strongly with parameters such as film stoichiometry and the presence of hydroxyl groups $[35,36,38]$. The ratio of UV to trap-state peak intensity is observed to increase with annealing in Fig. 5 for both film types. In particular, the intensity of the trap-state peak decreases considerably, which may be due to the desorption of surface impurities such as hydroxyl groups.

In the as-deposited films, the UV photoluminescence peak is located at approximately $362 \mathrm{~nm}(3.43 \mathrm{eV})$ for the pure aqueous deposition, whereas the UV peak is found at $359 \mathrm{~nm}(3.46 \mathrm{eV})$ for the film synthesized from the STM solution. When annealed, the 

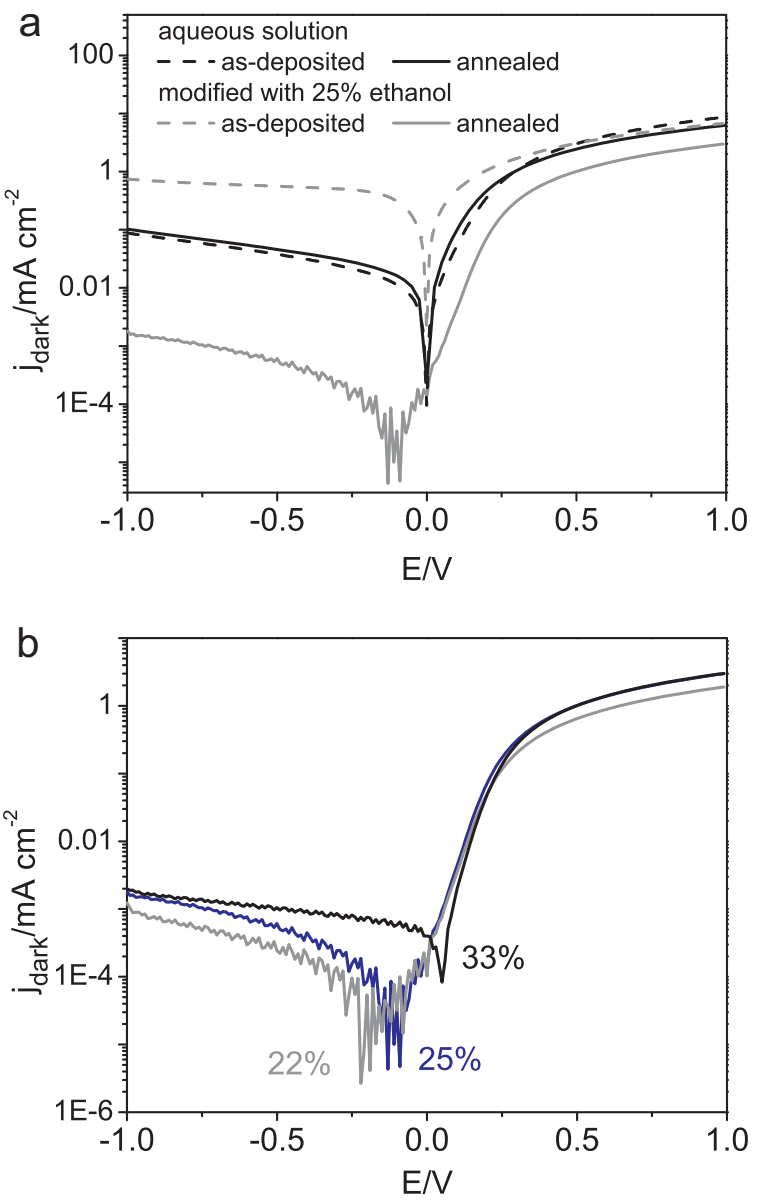

Fig. 6. Dark $j-E$ measurements of $\mathrm{n}-\mathrm{p} \mathrm{ZnO}-\mathrm{Cu}_{2} \mathrm{O}$ heterojunctions synthesized using ZnO films deposited from pure aqueous and STM zinc nitrate solutions. (a) The 'aqueous' diodes showed little improvement with annealing at $100^{\circ} \mathrm{C}$ for $1 \mathrm{~h}$ due to discontinuities in the $\mathrm{ZnO}$. The diodes synthesized with STM ZnO and annealed at $100{ }^{\circ} \mathrm{C}$ for $1 \mathrm{~h}$ to passivate defects at the heterojunction interface displayed much smaller reverse bias currents and much better rectification. (b) The built-in bias of the diodes was observed to vary with the volume concentration of ethanol used.

UV peaks for both film types were observed to shift to a longer wavelength of approximately $367 \mathrm{~nm}(3.38 \mathrm{eV})$. The bandgap of $\mathrm{ZnO}$ electrodeposited from zinc nitrate solutions has been shown previously to depend on nucleation and growth dynamics, varying with parameters such as film thickness and deposition potential [39], and to be influenced by impurities such as $\mathrm{Zn}(\mathrm{OH})_{2}$ [37]. The variation in UV emission observed here is likely attributable to defects and impurities that are passivated with annealing.

\section{2. $\mathrm{ZnO}-\mathrm{Cu}_{2} \mathrm{O}$ heterojunctions}

To demonstrate the dramatic influence that film homogeneity can have on the performance of relevant devices, functional $\mathrm{ZnO}$ layers synthesized from both pure aqueous and STM zinc nitrate solutions were employed in electrochemically synthesized diodes. Fig. 6 (a) displays $j-E$ measurements performed in the dark on $\mathrm{p}-\mathrm{n}$ heterojunctions formed by the electrodeposition of $3 \mu \mathrm{m}$ of $\mathrm{Cu}_{2} \mathrm{O}$ onto the $\mathrm{ZnO}$ layers. The $\mathrm{ZnO}$ synthesized using an aqueous solution was observed to have a typical concentration of bubble holes, whereas the film synthesized using a STM zinc nitrate solution was macroscopically continuous. Measurements were performed on the diodes both in their as-deposited form, as well as after annealing for approximately $1 \mathrm{~h}$ at $100^{\circ} \mathrm{C}$.

The $\mathrm{ZnO}-\mathrm{Cu}_{2} \mathrm{O}$ heterojunction fabricated with STM $\mathrm{ZnO}$ and annealed for $1 \mathrm{~h}$ displayed a drastically reduced reverse bias cur-

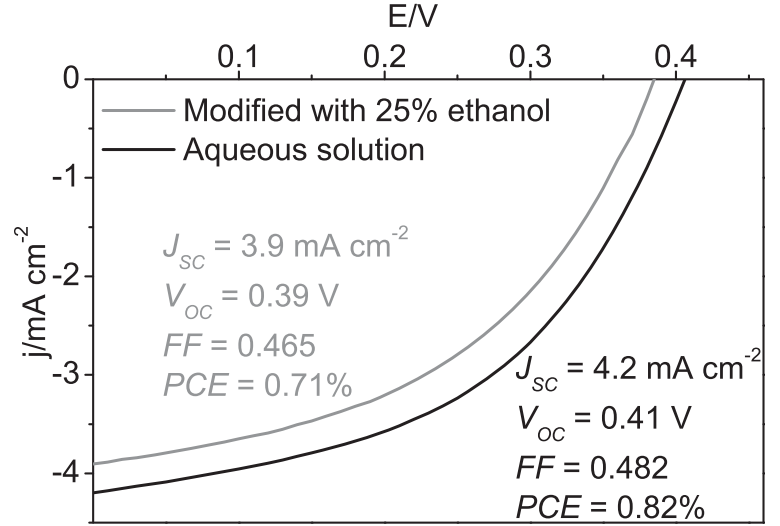

Fig. 7. Photovoltaic performance of as-deposited $\mathrm{ZnO}-\mathrm{Cu}_{2} \mathrm{O}$ heterojunctions with $\mathrm{ZnO}$ films synthesized from pure aqueous and STM zinc nitrate solutions.

rent (approximately two orders of magnitude smaller) and much better rectification than the equivalent aqueous junction. A rectification ratio (ratio of dark currents at $\pm 1 \mathrm{~V}$ ) of approximately 100 was obtained for the $\mathrm{ZnO}-\mathrm{Cu}_{2} \mathrm{O}$ heterojunction employing a $\mathrm{ZnO}$ film deposited from a traditional aqueous zinc nitrate solution, whereas a ratio greater than 1600 was observed for the heterojunction employing macroscopically continuous STM ZnO.

It is noted in Fig. 6 (a) that prior to annealing, a larger reverse bias current and weaker rectification were observed for the junction synthesized using a STM ZnO layer. When the STM ZnO films were annealed prior to junction fabrication $\left(\mathrm{Cu}_{2} \mathrm{O}\right.$ electrodeposition), a similarly poor rectification and large dark current was observed, which then improved with post-deposition annealing of the entire heterojunction. This suggests that the improvement in diode performance with annealing is not due to changes in the crystallinity of the $\mathrm{ZnO}$, but may instead be due to the passivation of defects at the $\mathrm{Cu}_{2} \mathrm{O}-\mathrm{ZnO}$ interface. Optimal lattice matching is known to result between $\mathrm{ZnO}\left(\begin{array}{lll}0 & 0 & 1\end{array}\right)$ and $\mathrm{Cu}_{2} \mathrm{O}$ (1111) lattice planes [28]. The reduction in 001 orientation observed in STM ZnO films in Fig. 4 may result in a greater density of strain-induced defects at the heterojunction interface, which require annealing to be alleviated.

In contrast, the heterojunctions utilizing $\mathrm{ZnO}$ layers deposited from traditional aqueous solutions showed no improvement with annealing, indicating that the performance of these diodes is limited by the presence of bubble holes in the $\mathrm{ZnO}$ layer, rather than by defects at the interface that can be thermally passivated. Discontinuities in the $\mathrm{ZnO}$ permit contact between the $\mathrm{Cu}_{2} \mathrm{O}$ and the underlying ITO, resulting in undesired leakage currents. Even if the crystallinity of the constituent materials and quality of the interface is improved with annealing, no reduction in reverse bias current is observed as a similar quantity of leakage current still passes through the pinholes in the $\mathrm{ZnO}$. The greater macroscopic continuity of the STM ZnO prevents these leakage currents, such that when heterojunctions employing STM ZnO are annealed briefly to remove defects at the interface, much lower reverse bias currents and much better rectification are realized. Current leakage is a common problem in many relevant devices, such that this simple technique to eliminate it will be extremely valuable.

A change in the built-in bias with annealing was noted in Fig. 6 (a) for the heterojunction using a STM ZnO layer. Furthermore, the built-in potential was observed to vary with the volume concentration of ethanol used, as shown in Fig. 6 (b). This may be due to the variation in $\mathrm{ZnO}$ orientation or morphology with ethanol addition, as previous studies have shown a significant influence of the interfacial orientation on $\mathrm{ZnO}-\mathrm{Cu}_{2} \mathrm{O}$ heterojunction properties [40-42]. Further study of such dependencies will be required in the future to more clearly define the influence of ethanol addition on the 
built-in potential of $\mathrm{ZnO}-\mathrm{Cu}_{2} \mathrm{O}$ heterojunctions electrochemically synthesized with zinc nitrate solutions.

Even in the absence of annealing, heterojunctions fabricated using STM ZnO were found to be suitable for photovoltaic devices. Fig. 7 shows $j-E$ data under AM $1.5 \mathrm{G}$ illumination for heterojunctions synthesized using $\mathrm{ZnO}$ deposited from pure aqueous and STM solutions. As these devices could be employed as low-cost solar cells fabricated on a variety of inexpensive (i.e. plastic) substrates, annealing treatments were avoided for this measurement. Despite the smaller rectification demonstrated in Fig. 6 (a) for as-deposited heterojunctions employing STM ZnO, only a small decrease in photovoltaic performance was observed. It is noted that it is difficult to correlate $j-E$ measurements performed in the dark with photovoltaic behaviour in these devices due to the photoconductive nature of the materials $[43,44]$. Device fabrication is expected to be more reproducible when STM ZnO films are employed, especially when conducting substrates prone to bubble formation are used.

\section{Conclusions}

Macroscopically uniform, compact $\mathrm{ZnO}$ films made by simple, low-temperature, solution-based techniques are necessary for many functional applications of $\mathrm{ZnO}$. In this work, it was demonstrated that perfectly continuous, polycrystalline $\mathrm{ZnO}$ films can be synthesized by a simple one-step electrodeposition technique from a $25 \% / 75 \%$ ethanol-water zinc nitrate solution. The addition of $25 \%$ ethanol (by volume) reduced the surface tension of the deposition solution, and eliminated the formation of bubbles on the substrate surface that introduce discontinuities in the growing films. Photoluminescence, XRD, and SEM investigations indicated microscopic properties similar to that of $\mathrm{ZnO}$ films deposited from pure aqueous solutions, with the exception of a reduction in 001 orientation. In all-electrochemically grown $\mathrm{ZnO}-\mathrm{Cu}_{2} \mathrm{O}$ heterojunctions, more than an order of magnitude reduction in the undesirable reverse bias current and more than an order of magnitude increase in the rectification ratio were observed when the perfectly continuous $\mathrm{ZnO}$ films synthesized from STM solutions were employed and the devices annealed briefly at $100^{\circ} \mathrm{C}$. This dramatic improvement was attributed to the elimination of leakage currents through bubble holes in the $\mathrm{ZnO}$, and was observed despite a reduction in the 001 orientation of the STM ZnO, which is expected to be best suited for $\mathrm{ZnO}-\mathrm{Cu}_{2} \mathrm{O}$ heterojunctions. While the change in $\mathrm{ZnO}$ orientation is relevant in some instances, many other applications of compact $\mathrm{ZnO}$ films, such as charge blocking layers in organic photovoltaics, are less sensitive to $\mathrm{ZnO}$ orientation. The synthesis of macroscopically uniform ZnO films using STM solutions will be particularly attractive in these cases, to prevent undesired shorting through pinholes. This work has demonstrated a valuable technique for the electrodeposition of functional $\mathrm{ZnO}$ layers of unprecedented uniformity from zinc nitrate solutions.

\section{Acknowledgements}

KPM, TG, and JLMD would like to acknowledge the International Copper Association, Peterhouse (Cambridge), the Natural Sciences and Engineering Research Council of Canada, the Higher Education Funding Council for England, the Gates Cambridge Trust, and the DAAD-British Council ARC project grant 1339. LSM would like to thank the German research foundation (DFG) for funding in the Cluster of Excellence "Nanosystems Initiative Munich (NIM)". The authors would also like to thank Diana Iza for assistance with photoluminescence measurements and analysis.

\section{References}

[1] R. Konenkamp, R.C. Word, M. Godinez, Nano Lett. 5 (2005) 2005.

[2] L. Schmidt-Mende, J.L. MacManus-Driscoll, Mater. Today 10 (2007) 40.

[3] A.K.K. Kyaw, X.W. Sun, C.Y. Jiang, G.Q. Lo, D.W. Zhao, D.L. Kwong, Appl. Phys. Lett. 93 (2008) 221107

[4] M. Izaki, T. Omi, Appl. Phys. Lett. 68 (1996) 2439.

[5] S. Peulon, D. Lincot, Adv. Mater. 8 (1996) 166.

[6] S. Peulon, D. Lincot, J. Electrochem. Soc. 145 (1998) 864

[7] J. Elias, R. Tena-Zaera, C. Levy-Clement, J. Electroanal. Chem. 621 (2008) 171.

[8] Z.H. Gu, T.Z. Fahidy, R. Hornsey, A. Nathan, Can. J. Chem. 75 (1997) 1439.

[9] Z.H. Gu, T.Z. Fahidy, J. Electrochem. Soc. 146 (1999) 156.

[10] M. Izaki, J. Electrochem. Soc. 146 (1999) 4517.

[11] M. Izaki, S. Watase, H. Takahashi, Adv. Mater. 15 (2003) 2000.

[12] B. Cao, W. Cai, H. Zeng, G. Duan, J. Appl. Phys. 99 (2006) 073516.

[13] S. Otani, J. Katayama, H. Umemoto, M. Matsuoka, J. Electrochem. Soc. 153 (2006) C551.

[14] M. Wang, S.J. Chua, H. Gao, J.S. Leib, C.V. Thompson, J. Electrochem. Soc. 156 (2009) D517.

[15] I. Zhitomirsky, Adv. Colloid Interface Sci. 97 (2002) 279

[16] H. Van Parys, G. Telias, V. Nedashkivskyi, B. Mollay, I. Vandendael, S. Van Damme, J. Deconinck, A. Hubin, Electrochim. Acta 55 (2010) 5709.

[17] G.-R. Li, C.-R. Dawa, Q. Bu, X.-H. Lu, Z.-H. Ke, H.-E. Hong, F.-L. Zheng, C.-Z. Yao, G.-K. Liu, Y.-X. Tong, J. Phys. Chem. C 111 (2007) 1919.

[18] C.-L. Cheng, J.-S. Lin, Y.-F. Chen, J. Alloys Compd. 476 (2009) 903

[19] Th. Pauporté, D. Lincot, J. Electroanal. Chem. 517 (2001) 54.

[20] J. Yang, Y. Qiu, S. Yang, Cryst. Growth Des. 7 (2007) 2562.

[21] J. Rappich, M. Fahoume, Thin Solid Films 487 (2005) 157.

[22] H. Yan, Y. Yang, Z. Fu, B. Yang, L. Xia, S. Fu, F. Li, Electrochem. Commun. 7 (2005) 1117

[23] K.P. Musselman, A. Wisnet, D.C. Iza, H.C. Hesse, C. Scheu, J.L. MacManus-Driscoll, L. Schmidt-Mende, Adv. Mater. 22 (2010) E254.

[24] K.P. Musselman, A.T. Marin, A. Wisnet, C. Scheu, J.L. MacManus-Driscoll, L. Schmidt-Mende, Adv. Funct. Mater. 21 (2011) 573.

[25] J.Y. Lee, Y.S. Choi, J.H. Kim, M.O. Park, S. Im, Thin Solid Films 403 (2002) 553.

[26] Y.I. Alivov, E.V. Kalinina, A.E. Cherenkov, D.C. Look, B.M. Ataev, A.K. Omaev, M.V. Chukichev, D.M. Bagnall, Appl. Phys. Lett. 83 (2003) 4719.

[27] S. Chu, M. Olmedo, Z. Yang, J. Kong, J. Liu, Appl. Phys. Lett. 93 (2008) 181106.

[28] M. Izaki, T. Shinagawa, K.T. Mizuno, Y. Ida, M. Inaba, A. Tasaka, J. Phys. D: Appl. Phys. 40 (2007) 3326.

[29] H.-J. Liaw, Y.-Y. Chiu, J. Hazard. Mater. 137 (2006) 38.

[30] G. Vazquez, E. Alvarez, J. Navaza, J. Chem. Eng. Data 40 (1995) 611.

[31] B.E. Prasad, P.V. Kamath, J. Solid State Electrochem. 14 (2010) 2083.

[32] Z. Chen, A. Ni, F. Li, H. Cong, H. Cheng, G.Q. Lu, Chem. Phys. Lett. 434 (2007) 30.

[33] W. Bai, X. Zhu, Z. Zhu, J. Chu, Appl. Surf. Sci. 254 (2008) 6483.

[34] X. Zhang, S. Hou, H. Mao, J. Wang, Z. Zhu, Appl. Surf. Sci. 256 (2010) 3862

[35] A.B. Djurisic, A.M.C. Ng, X.Y. Chen, Prog. Quantum Electron. 34 (2010) 191.

[36] J. Qiu, X. Li, W. He, S.-J. Park, H.-K. Kim, Y.-H. Hwang, J.-H. Lee, Y.-D. Kim, Nanotechnology 20 (2009) 155603.

[37] Q. Wang, G. Wang, J. Jie, X. Han, B. Xu, J.G. Hou, Thin Solid Films 492 (2005) 61.

[38] B.J. Jin, S.H. Bae, S.Y. Lee, S. Im, Mater. Sci. Eng. B 71 (2000) 301.

[39] R.E. Marotti, D.N. Guerra, C. Bello, G. Machado, E.A. Dalchiele, Sol. Energy Mater. Sol. Cells 82 (2004) 85.

[40] K. Akimoto, S. Ishizuka, M. Yanagita, Y. Nawa, K.P. Goutam, T. Sakurai, Sol. Energy 80 (2006) 715.

[41] S. Jeong, A. Mittiga, E. Salza, A. Masci, S. Passerini, Electrochim. Acta 53 (2008) 2226.

[42] S.-M. Chou, M.-H. Hon, I.-C. Leu, Y.-H. Lee, J. Electrochem. Soc. 155 (2008) H923.

[43] G.P. Pollack, D. Trivich, J. Appl. Phys. 46 (1975) 163.

[44] J. Reemts, A. Kittel, J. Appl. Phys. 101 (2007) 013709. 